\title{
Application of Remote Sensing Method for Geological Interpretation of Sokoto Plain, Nigeria
}

\author{
Aisabokhae Joseph ${ }^{1}$ and Oresajo Bamidele ${ }^{2}$ \\ ${ }^{1}$ Department of Applied Geophysics, Federal University Birnin Kebbi, Nigeria, \\ joseph.aisabokhae@fubk.edu.ng \\ ${ }^{2}$ Department of Geology, Federal University Birnin Kebbi, Nigeria
}

\section{DOI: http://dx.doi.org/10.4314/sajg.v7i3.12}

\begin{abstract}
Landsat-8 OLI imagery of Sokoto, Nigeria, was processed to emphasize the geology features and mineral potential of the area. Band ratios $\left(\frac{4}{2}, \frac{5}{6}, \frac{6}{7}\right)$ were assigned to RGB. Band ratio $\frac{4}{2}$ highlights ferric ion minerals, $\frac{5}{6}$ emphasizes ferrous minerals, and $\frac{6}{7}$ distinguishes iron oxide minerals from carbonate minerals. In a second technique, band ratio $\frac{6}{7}$ was replaced with $\frac{7}{5}$ in order to accentuate clay minerals with high reflectance within band 7. The last technique evaluated in this study used spectral information from minimum noise fraction image to map surface geology. Supervised classification training sites were selected using five classes (clay, ironstone, alteration zone, water and vegetation). The band ratio classification using maximum likelihood classification was fairly accurate and matched the geologic map of the area, also showing an alteration zone that coincided with the migmatite-quartz/mica schist contact. The classified image was finally passed through a filtering effect for generalization of the data. This filtering effect was helpful in discriminating the pixels of ironstone and those of the alteration zone on the classified map. This study shows the distribution of classified earth-surface materials in Sokoto plain with the aid of supervised classification of Landsat-8 multispectral bands interpreted to reflect in-situ features.
\end{abstract}

Keywords; Landsat-8 imagery, Sokoto, mineral potential, supervised classification

\section{Introduction}

Sokoto State is the sixteenth largest state, occupying an area estimated to be $25,973 \mathrm{~km}^{2}$, with a vast majority of its local geology poorly understood. Unearthing the details of the local geology in this area could be key to unlocking the vast secrets of mineral potential and exploration prospectivity. Indigent geologists, prominent among them being Kogbe (1979), mapped and defined the macro geologic elements of Sokoto with several inconclusive investigations carried out in the region since then as regards mineral potentiality.

However, improvement on previously established research can be made to enhance and clearly differentiate geologic units and structures, and advance the understanding and definition 
of specific remote sensing data attributes useful for geologic discrimination in Sokoto and similar terrains.

Remote sensing involves inferring surface parameters from measurements of the electromagnetic radiation from the surface of the earth. It entails detecting and measuring electromagnetic energy emanating or reflected from distant objects made of various materials to identify and categorize these objects by class or type, substance and spatial distribution (Vincent, 1997). Multispectral datasets can be used to map altered rocks including clay and iron minerals. These minerals can be detected directly from satellite images, however, the depth and burial extent are subjects of further geophysical investigations (El Khidir, 2006). The key elements in mineral prospecting are to gain understanding of the geology of the area through lithological mapping and to assist in defining potential target areas.

Primary remote sensing techniques that have recently been put to use for mapping soil and rock outcrop from the conventional resolution imagery include single band combination, band ratioing, minimum/maximum noise fraction processing (MNF), image classification and several suitable functions necessary to highlight prospects (Khalid et al., 2014). Single band combination is the merging of three separate spectral bands into a single image to reflect the three dominant surface spectral signatures in red, green and blue coloration. Band ratio can be useful for highlighting certain features or materials that can not be observed in the raw bands. Band ratio is a technique where the digital number value of one band is divided by the digital number value of another band. While MNF is a processing technique that helps to reduce dimensionality in a dataset, image classifications are performed in order to categorize the pixels of an image into different classes or themes in order to produce a thematic map (El Khidir, 2006). The image supervised classification process is composed mainly of three stages; the training stage where the analyst identifies representative training areas and develop a numerical description or class of spectral attributes of each land cover type of interest in the scene. In the classification stage, each pixel in the image data set is categorized into the land cover class it most closely resembles. The output stage is the result that categorizes the entire data (Gupta, 2003).

The multispectral data analysis presented in this research would build a link to several ongoing field-based lithostratigraphical, geochronological and geochemical studies of the Sokoto Sector under three broad perspective: The first is palynologic studies and age determination of the Continental Intercaleir, a subject that relates to the investigation of sporo-pollinitic content and probable age of the formation. The second is the analysis involving granulometric, clay mineral and heavy metal constituents. The third is the correlation with other areas and palaeogeographic conclusions recorded from previous studies.

Primarily, this research aims to analyse remote sensing data to map and identify categories and spectral signatures of particular observable features of areas within the Sokoto Sector of the Iullemmeden Basin hosting both sedimentary formations and the Precambrian basement 
complex within the Pan African mobile belt. The study area contains several mineral prospects and outcrops of clay deposits including ilmenite and kaolinite. This paper aims to differentiate and accentuate geologic units and enhance the understanding of specific remote sensing data processing useful for feature discrimination in Sokoto, Nigeria.

\section{Description of the study area}

Sokoto state is located in the northwestern part of Nigeria as shown in Figure 1. In Northwestern Nigeria, the sediments of the Iullemmeden Basin were deposited during three main phases: continental Mesozoic and Tertiary phases with an intervening marine Maastrichtian to Paleocene phase. Overlying the Precambrian basement conformably, the Illo and Gundumi Formations, made up of grits and clay from parts of the Continental Intercalier of West Africa. They are overlain uncornformably by the Maastrichtian Rima Group, consisting of musdstone and friable sandstones separated by a fossiliferous shaly formation (Odeyemi, 1981).

The geological structure of the Sokoto basin is without much complexity (Figure 2). The beds are free from faulting, with dips between 2.5 to 3.8 meters per kilometre in a direction $60^{\circ}$ west of north. Around Sokoto the direction of dip is about $18^{\circ} \mathrm{NW}$. The sedimentary deposits lie on the crystalline Precambrian basement, consisting of gneisses, granite, phyllites and quartzites. The basement rocks outcrop in the eastern and southern sector of Sokoto state (Kogbe, 1999).

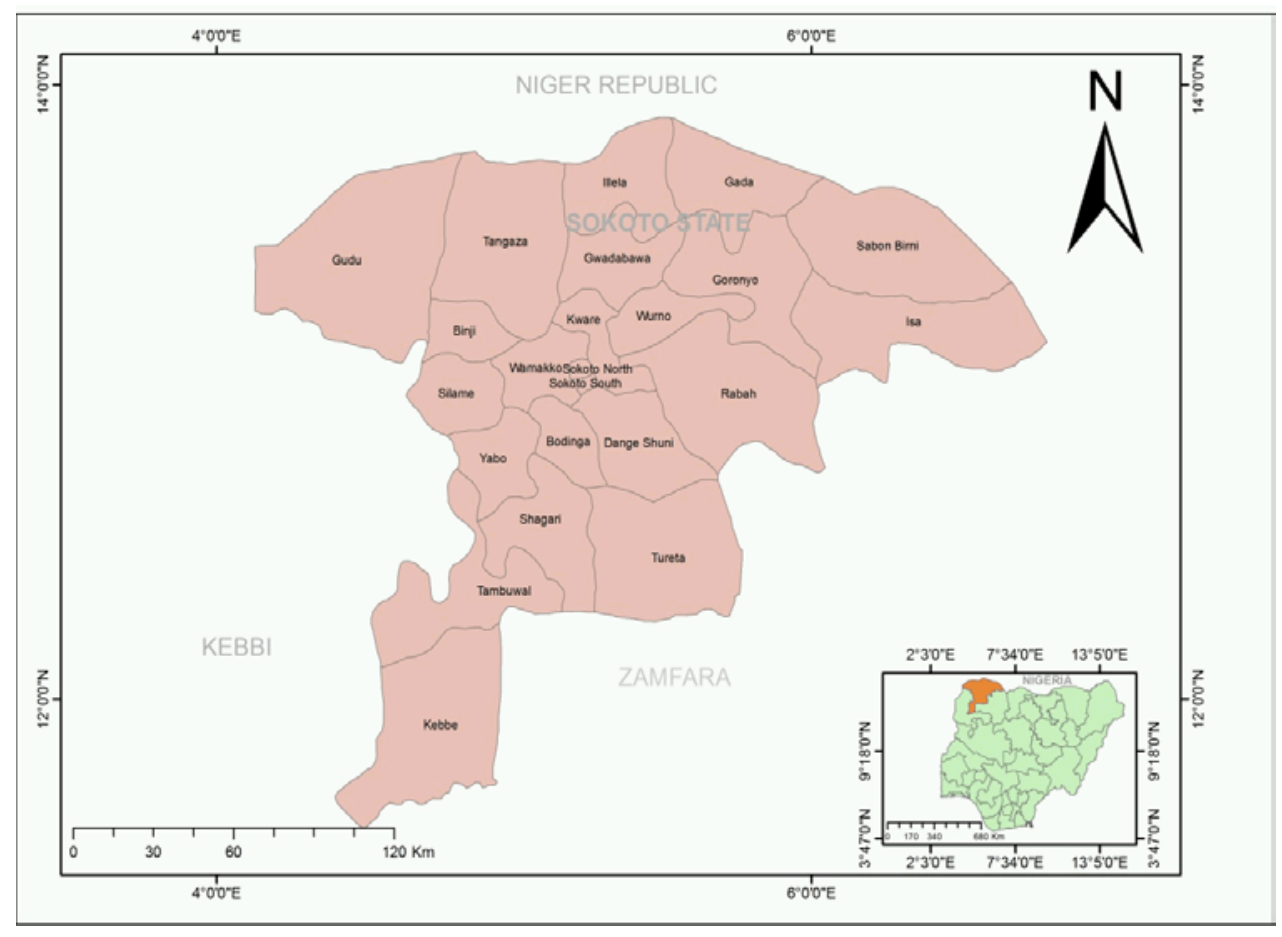

Figure 1: Geographical location map of Sokoto. Inset shows general map of Nigeria (modified after Furon, 1963) 


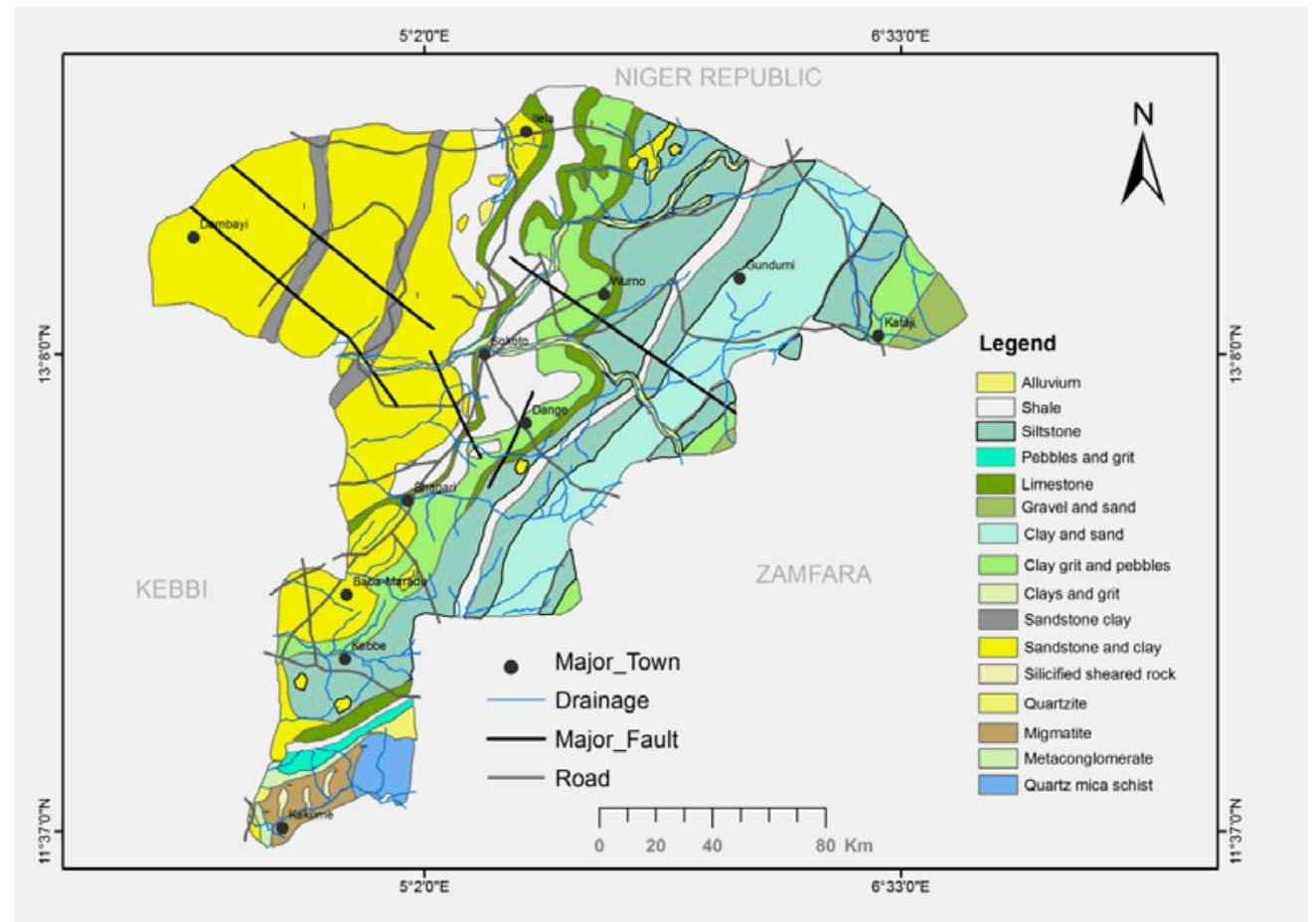

Figure 2: Map of Sokoto showing major geological units and structures (modified after Furon, 1963)

The soils in the area are formed dominantly over gneiss and possess varying degrees of development and texture depending on the age of the formation and where they are deposited. Exposed clay outcrop are common while ironstone capping is predominant in areas transiting the basement complex. The iron-rich oolites are primary deposits and deposition of ferruginous materials occurred during the late Paleocene. The crusty laterites and ferruginous sandtone were formed during the late Tertiary to early Quaternary. They are definitely post-Miocene in age and consist of abundant quartz grains embedded in matrix of goethite, haematite, limonite and clay (Kogbe, 1979).

\section{Materials and Methods}

\subsection{Image Acquisition and Preprocessing}

Four Landsat-8 OLI/TIR scenes (path 190, row 051), (path 190, row 052), (path 191, row 051) and (path 191, row 052) with 0\% cloud cover were acquired for the year 2017 from the US Geological Survey. All four Level 1T standard terrain corrected images were processed using the Environment for Visualizing Images (ENVI) version 5.1 software and Environment Systems Research Institute (ESRI) ArcGIS version 10.1 software. The Landsat images were spectrally subset to contain OLI bands of Band 1 (coastal/aerosol, $0.433-0.453 \mu \mathrm{m}$ ), Band 2 (blue, $0.450-0.515 \mu \mathrm{m}$ ), Band 3 (green, $0.525-0.600 \mu \mathrm{m}$ ), Band 4 (red, $0.630-0.680 \mu \mathrm{m}$ ), Band 5 (NIR, $0.845-0.885 \mu \mathrm{m})$, Band 6 (SWIR, $1.560-1.660 \mu \mathrm{m})$, Band 7 (SWIR, 2.100 - 
2.300 $\mu \mathrm{m}$ ), Band 8 (panchromatic, $0.500-0.680 \mu \mathrm{m}$ ) and Band 9 (cirrus, $1.360-1.390 \mu \mathrm{m}$ ). Landsat images were converted to calibrated radiance then converted to surface reflectance in Fast Line-in-sight Atmospheric Analysis Spectral Hypercube (FLAASH) for the purpose of facilitating multi-date scene comparisons and multitemporal stacking. Finally, the mosaicked scenes were spatially subset to Sokoto using a shapefile in order to focus classification efforts on the study area. The effect of cloud cover was minimal as there was no cloud cover influence on the data.

\subsection{Image Processing}

In this research, several image processing techniques were applied on the data in order to enhance multispectral characteristics of the study area in terms of geological mapping. The preparation and enhancement of the image was done by contrast stretching method. This processing method is designed to transform multispectral image data format into an image display that either increases contrast between interesting targets and the background or yields information about the composition of certain pixels in the image (Khalid et al., 2014). Image processing techniques applied in this study included single band combination (colour composite), band ratioing, minimum noise fraction (MNF) and supervised classification of the multispectral data.

\subsubsection{Single Band Combination}

Natural red, green and blue (RGB) colour combination image can highlight geological features including textural characteristics and the igneous and sedimentary rocks, structural features and vegetation at regional scale (Sabins, 1999). Based on laboratory spectra of minerals related to clay minerals, ferric ion and ferrous ion minerals, several Red-Green-Blue colour combination images can be created using Landsat-8 data.

The first spectral band of Landsat-8 $(0.433-0.453 \mu \mathrm{m})$ is designed as a deep-blue band for coastal water and aerosol studies, so it cannot be used to detect geological features. Band 1 is thus excluded from RGB colour combination image in this study. A single RGB image is first produced for visible bands (2, 3 and 4 ) of Landsat-8 data as seen in figure 2. Band 2 is positioned in the blue $(0.450-0.515 \mu \mathrm{m})$, band 3 in green $(0.525-0.600 \mu \mathrm{m})$ and band 4 in red $(0.630-$ $0.680 \mu \mathrm{m})$ regions of the electromagnetic spectrum. The band $5(0.845-0.884 \mu \mathrm{m})$ is the near infra-red band while the short wavelength infra-red band are $6(1.560-1.660 \mu \mathrm{m})$ and $7(2.100$

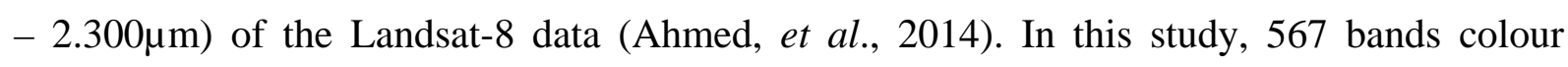
composites (Figure 3) were generated for the purpose of lithological mapping. This was done by importing individual 8-bit gray-scale surface reflectance bands of the Landsat-8 data into ENVI workspace. The operation was then followed by calculating for Optimal Index Factor to select the most informative colour composite images on ILWIS. With all the bands ranked 
according to spectral quality, the brightest bands were then combined and displayed in RGB using the ENVI software.

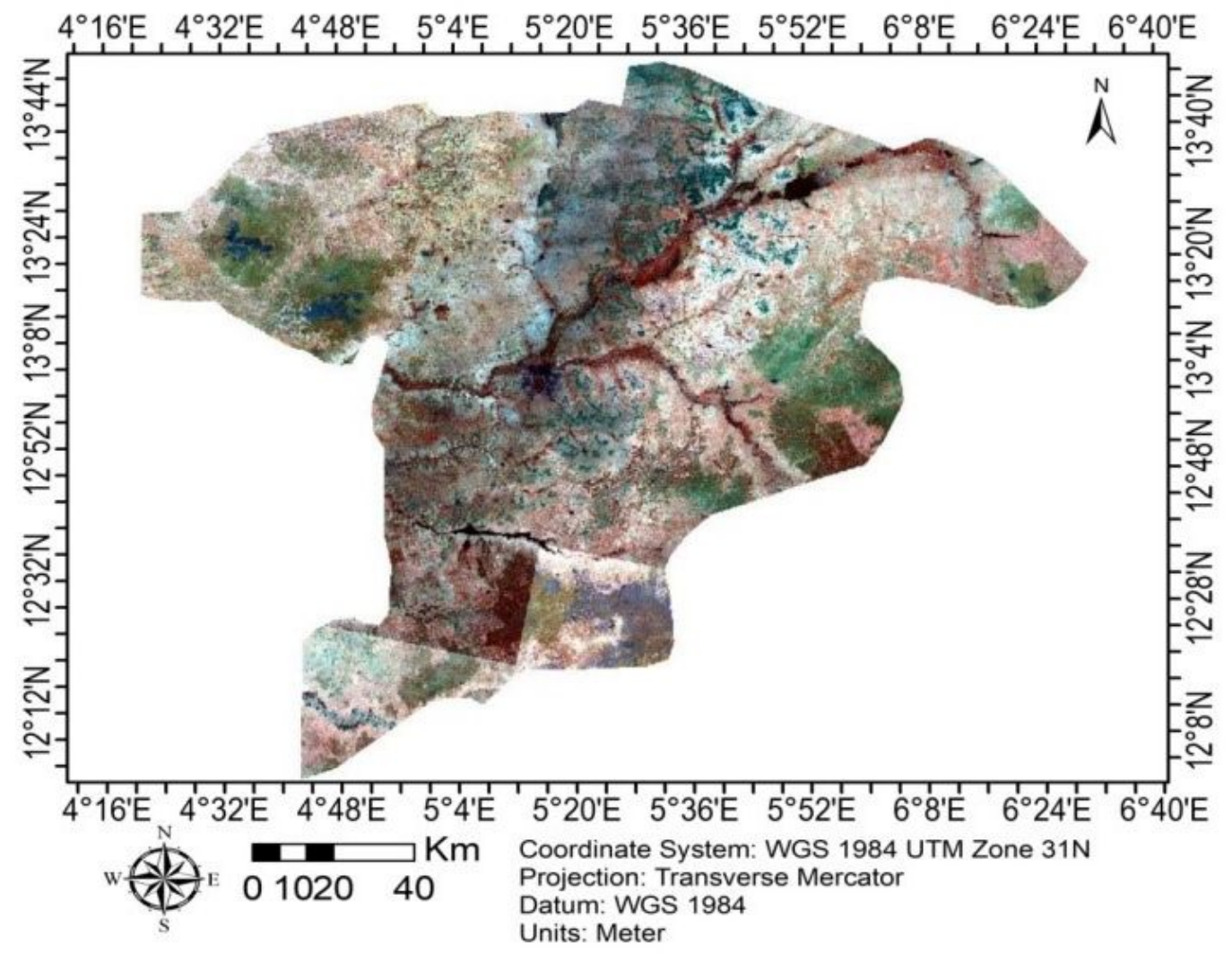

Figure 3: Single band combination for 567 bands

\subsection{2. $\quad$ Band Ratio}

Band ratio is a simple technique where the digital number (DN) value of one band is divided by the digital number value of another band (Sabins, 1999). Band ratios are very useful for highlighting certain features or materials that cannot be seen in the raw band. This operation was performed by selecting the band with high reflectance for a mineral as the 'numerator' and another band with high absorption as the 'denominator' in the ENVI software band ratio interface. Three ratios were performed and each pair was assigned to RGB respectively. The ratio $4 / 2$ is useful for mapping iron oxides because it has absorption in the blue region and high reflectance in the red region. The ratio $5 / 6$ was used for mapping ferrous minerals due to high reflectance of those minerals in the band ratio. Either of ratio $6 / 7$ or $7 / 5$ can highlight clay minerals in multispectral images (Ahmed, et al., 2014). All three ratios were merged using RGB colour representation to produce a band ratio map as seen in Figures 4 and 5. 


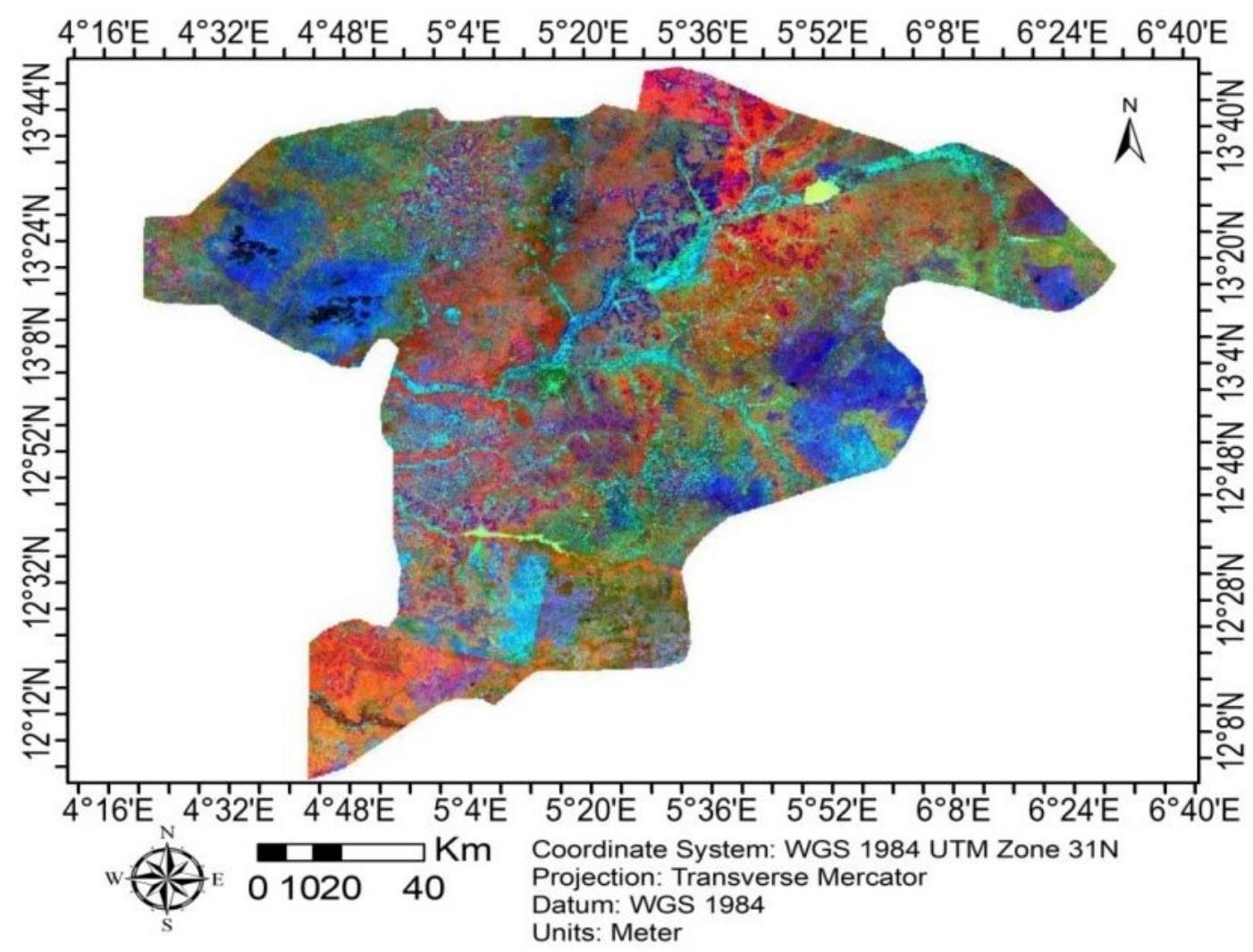

Figure 4: Landsat 8 band ratio $\left(\frac{4}{2}, \frac{5}{6}, \frac{6}{7}\right)$ for RGB

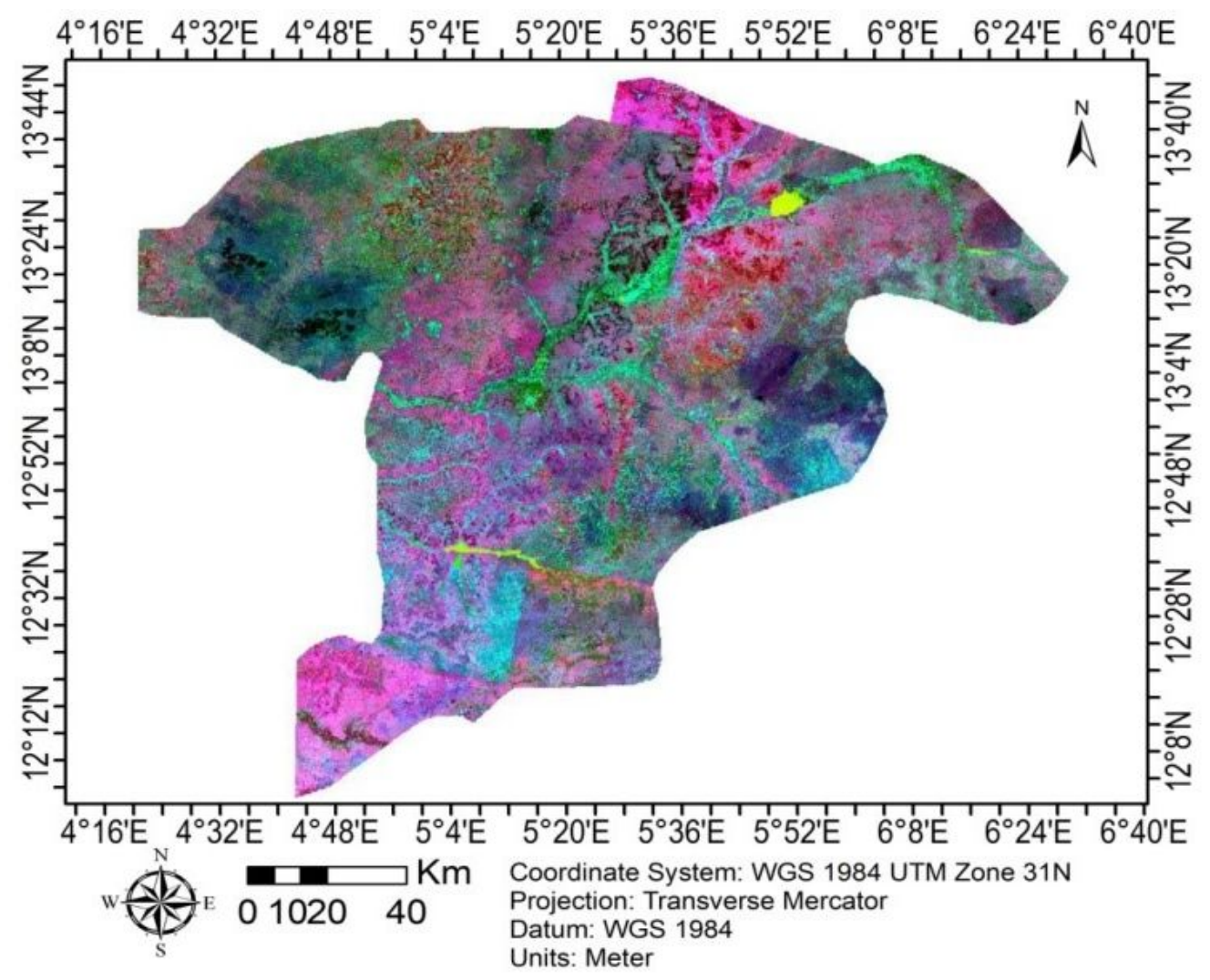

Figure 5: Landsat 8 band ratio $\left(\frac{4}{2}, \frac{5}{6}, \frac{7}{5}\right)$ for RGB 


\subsubsection{Minimum Noise Fraction}

This method which was developed by Green et al (1988) is similar to principal component orthogonalization rotation that results in components ordered in increasing rank of random noise rather than decreasing rank of variance. So, the MNF transform is used to determine the inherent dimensionality of image data, to segregate and equalise the noise in the data, and to reduce the computational requirements in the case of subsequent processing. This technique was used in Figure 6 to identify clay mineral outcrops in the image with the help of pansharpening technique. MNF was performed in this study to extract individual mineral species from a mixed pixel spectrum, in theory providing geologist with the capability to map mineral surface composition. Although this image processing method has been mostly applied on hyperspectral data, they can also be applicable logically to multispectral data. With these image processing methods, pixels that have mixed spectral signatures will be extractable and can be separated from the undesirable background. Thus, mineral abundance maps can be produced free of diluting effects of surrounding environment. MNF approach for analysis of multispectral data used in this work is implementable and documented within the ENVI software system. The analysis approach consists of spectral compression, noise suppression and dimensionality reduction using the Minimum Noise Fraction (MNF) transformation. MNF component images show steadily decreasing image quality with increasing band number, so images with higher eigenvalues contain higher spectral information (Gupta, 2003). RGB colour combination image was assigned to three high eigenvalues MNF transformed bands. Figure 6 shows the resultant image. 


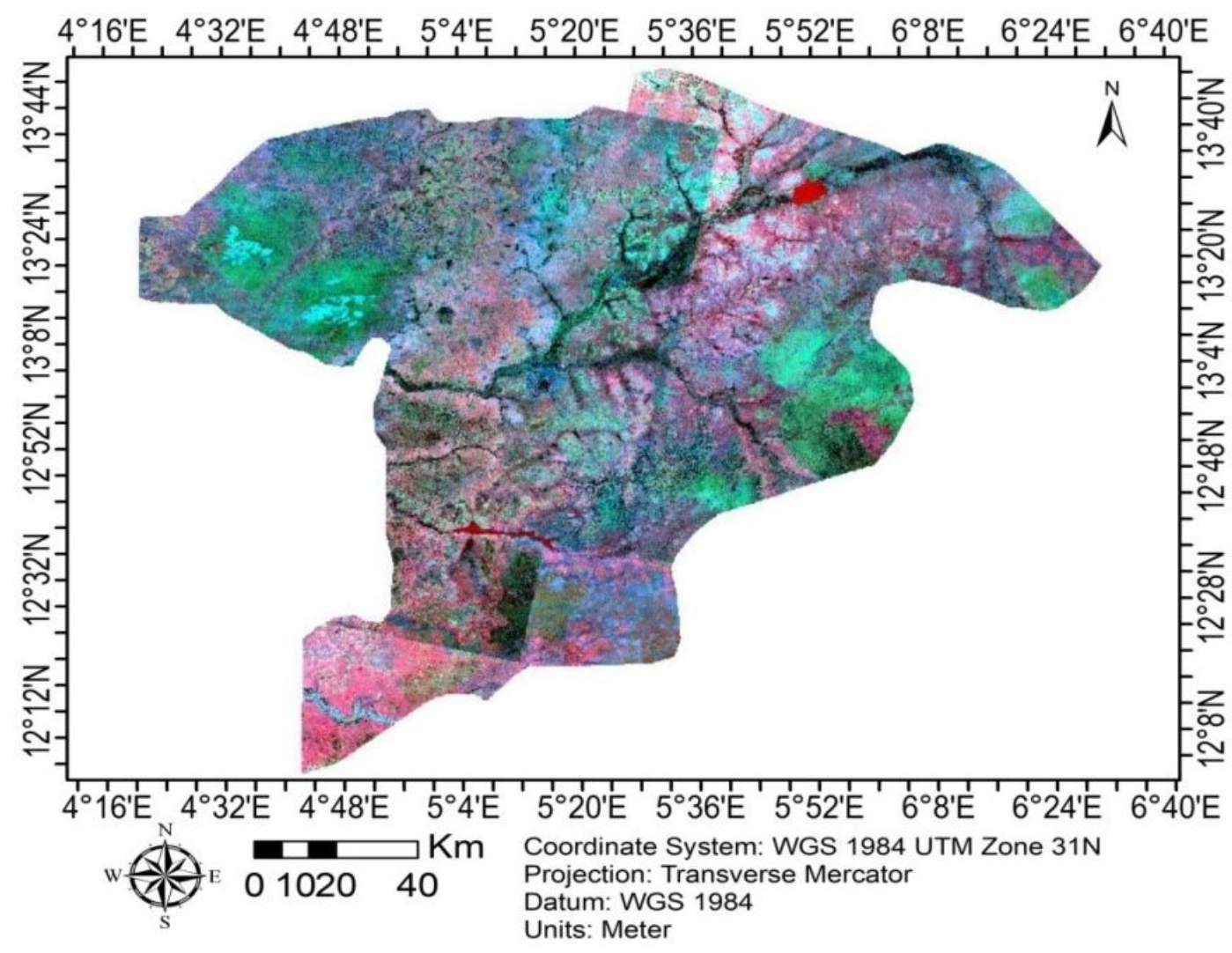

Figure 6: Band 123 from MNF result

\subsubsection{Image Classification}

Classification is a key procedure for creating information from data. Image analysis classification identifies pixels with similar spectral signatures through statistical analysis of multiband images (Ahmed, et al., 2014). Groups of pixels with similar spectral signatures can be identified as features based on their geometric relationships and the knowledge and interpretive skills of the analyst.

Supervised classification utilizes class information input by the analyst before statistical analysis and classification of the image. Selected training samples contain pixels that represent the spectral characteristics of only the feature or feature class to be identified. Several training samples can be selected and combined to make a single class. In this work, the selection of training sites was done using the region of interest tool in ENVI. Visual selection with the masking of wadies, water, soil and vegetation was performed using the maximum likelihood method for supervised classification. The number of proposed classes was requested after which shapefiles were created for the respective classes used in Figure 6. 


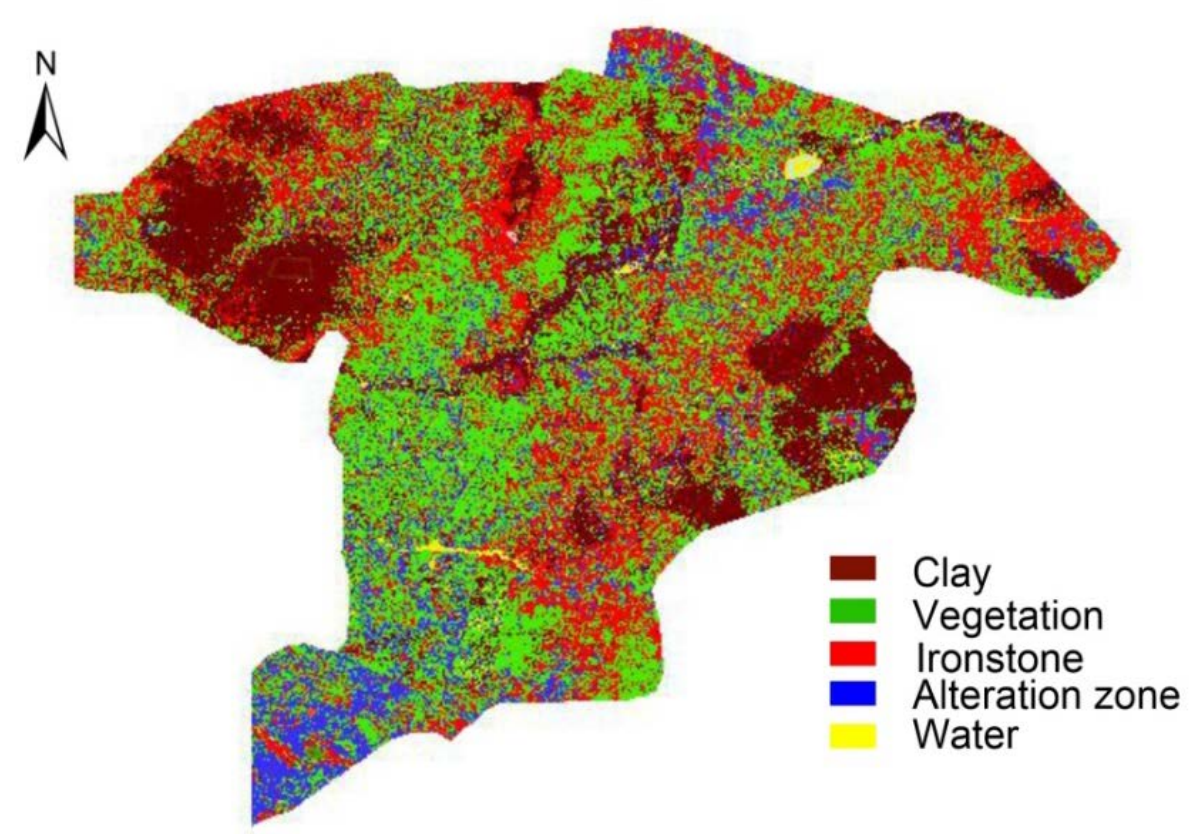

Figure 6: Classified Landsat-8 band ratio $\left(\frac{4}{2}, \frac{5}{6}, \frac{6}{7}\right)$ image

\section{Result and Discussion}

Multispectral images of Landsat-8 data were processed to interpret for geological studies of the survey area. The image from colour composite technique showed a good result in terms of lithological mapping. Mapping iron oxides was carried out using bands 2 and 4 because iron oxide/hydroxide minerals such as hematite, jarosite and limonite, and sulphuric minerals have high reflectance within $0.63-0.69 \mu \mathrm{m}$ (band 4 ) and high absorption within $0.45-0.52 \mu \mathrm{m}$ (band 2). Clay and carbonate minerals have absorption features from $2.1-2.4 \mu \mathrm{m}$ (band 7) and reflectance from 1.55 - 1.75 $\mu$ m (band 6) in Landsat-8 data (Han et al., 2015). Minerals such as alunite, and clay minerals such as illite, kaolinite and montmorillonite have distinctive absorption features at 2.20 $\mu \mathrm{m}$ and low absorption at $1.6 \mu \mathrm{m}$, hence, band ratio of 6 and 7 , and 7 and 5 were calculated to map clay deposits as dark blue in figure 4 and figure 5 . Band ratios derived from image spectra $\left(\frac{4}{2}, \frac{5}{6}, \frac{6}{7}\right)$ and $\left(\frac{4}{2}, \frac{5}{6}, \frac{7}{5}\right)$ (figure 4 and 5 respectively) in RGB allow the identification of altered rocks, lithological units and drainage.

From the MNF transformed image, reddish areas are dominated by limonite minerals (hematite, geotite and jarosite), the bluish areas are dominated by Fe-Mg silicate minerals like olivine, pyroxenes and amphiboles while the greenish areas are dominated by clay minerals, micas and talco-carbonates.

Supervised image classification using maximum likelihood classification was applied to band image $\left(\frac{4}{2}, \frac{5}{6}, \frac{6}{7}\right)$ in this study. Five selected training samples containing pixels that represent the spectral characteristics of features of interest were identified. The five classes where categorised as clay, ironstone, alteration zone, water and vegetation. A final operation 
on the classified data for cleaning and generalizing the data was performed. This procedure which has filtering effect on the data reduces the noise especially if the data was processed to detect change.

The result of this classification of the Landsat band ratio data appears to fairly accurately represent the surface geologic character in comparison to the geologic map and in the original band ratio image. In the Landsat band ratio classified image, many pixels are displayed in green (vegetation). In contrast, the results of the band ratios $\left(\frac{4}{2}, \frac{5}{6}, \frac{6}{7}\right)$ and $\left(\frac{4}{2}, \frac{5}{6}, \frac{7}{5}\right)$ products appear to have some significant differences from the image classification product. For example, the pixels classified as alteration zones (blue) in the image classification product are different from the pixels classified as ironstone capping (red) but both classes are assumed to have the same spectral signature in the MNF and band ratio images. The alteration zone which is indicative of ferric ion minerals appear to be dominant in the extreme south of the image classification map and this is consistent with the location of migmatite - quartz/mica schist boundary in the geologic map situated near the sedimentary-basement contact within the Iullemmeden Basin. Of more interest is the precise classification of clay minerals in the image classification mapped in similar location and distribution as clay deposits in the band ratio images. Drainage which appears as yellow colour in the classified image was colour red in the MNF image and light green in both band ratio images. This perfect fit shows that the training classes perfectly represented the ground truth data. However, the expansive drainage pattern is not obvious in the geologic map of the study area.

\section{Conclusion}

Remote sensing method employing techniques such as band combination, band ratio and supervised image classification can be an appropriate tool in mapping the geology and structure of a vast region of area especially when combined with field investigations. Based on the classification method used (maximum likelihood classification), the band ratio $\left(\frac{4}{2}, \frac{5}{6}, \frac{6}{7}\right)$ produced an accurate classification of the geology of Sokoto state. The number of observable spectral signatures on the band ratio image determined the number of training site classes used in the image classification in this study.

\section{References}

Ahmed, S. \& Amin, B. 2014. Lithological mapping and hydrothermal alteration using Landsat 8 data: a case study in Ariab mining district, red sea hills, Sudan. Intl. J. Basic and Appld. Sci., 3(3), 199208

Crosta, A. \& De Souza Filho, C. 2009. Mineral exploration with Landsat Thematic Mapper (TM) / Enhanced Thematic Mapper plus (ETM+): A review of fundamentals, characteristics, data processing, and case studies. Rev.in Econ. Geol., 16, 59-82 
El Khidir, S. 2006. Remote Sensing and GIS Applications in Geological Mapping, prospecting for minerals deposits and groundwater Berber Sheet Area, Northern Sudan (Ph. D. Thesis). Al Neelain University, Khartoum, Sudan

Furon, R. 1963. Geology of Africa, Oliver and Boyd, England

Green, A., Berman, M., Switzer, P., Craig, M. 1988. A transformation for ordering multispectral data in terms of image quality with implications for noise removal: IEEE Transactions on Geoscience and Remote Sensing, 26(1), 65-74

Gupta, R.P. 2003. Remote sensing geology, Springer, 2nd edition, Germany. 31-33

Han, T. \& Nelson, J. 2015. Mapping hydrothermally altered rocks with Landsat-8 imagery: A case study in the KSM and Snow field zones, northwestern British Columbia. In: Geological Fieldwork 2014, British Columbia Ministry of Energy and Mines, British Columbia Geological Survey Paper Vol. 1, 103-112.

Khalid, A. \& Abdel, H. 2014. The use of Landsat 8 OLI Image for the delineation of Gossanic Ridges in the Red Sea Hills of NE Sudan. American J. of Earth Sci., (1)3, 62-67

Kogbe, C. 1979. Geology of the south eastern sector of the Iullemmeden Basin. Bulletin of Geology Department. ABU Zaria, (2)1, 44-63.

Odeyemi, I.B. 1981. A review of orogenic events in the Precambrian basement of Nigeria, West Africa. Geologische Rundschau, (70)3, 897-909

Rockwell, B. \& Hofstra, A.H. 2008. Identification of quartz and carbonate minerals across northern Nevada using ASTER thermal infrared emissivity data Implications for geologic mapping and mineral resource investigations in well-studied and frontier areas, Geosphere, 4(1), 218-246.

Sabins, F. 1999. Remote sensing for mineral exploration, Ore Geology Review, 14, 157-183

Sploos, L.L. \& Speed, R.C. 1974. Relationship of cratonic and continental margin tectonic episodes. In: Dickinsen, E. (Ed): Tectonics and sedimentation. Spec. Publ. Soc. Econ. Paleont. Min., 22, 98 -119

Vanhellemont, P. \& Ruddick, M. 2013. Landsat-8: Science and product vision for terrestrial global change research. Rem. Sens. of Environ., 145, 154-172.

Vincent, R.K. 1997. Fundamentals of Geological and Environmental Remote Sensing, Prentice Hall, Upper Saddle River, NJ, p80121

Wright, J.B. 1985. Geology and mineral resources of West Africa. George Allen and Unwin, London. pp187 